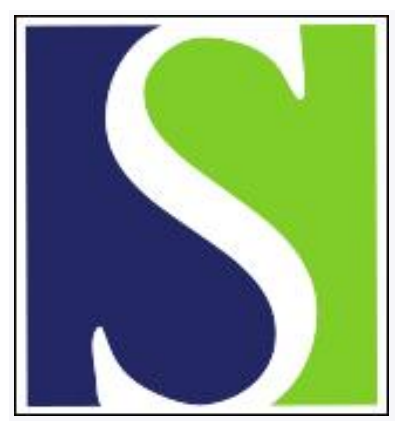

Scand J Work Environ Health 2019;45(2):209-210

https://doi.org/10.5271/sjweh.3779

Published online: 24 Oct 2018, Issue date: 01 Mar 2019

Positive association between job decision authority and systolic blood pressure: a statistical artifact?

by Choi $B$, Juárez-Garcia $A$

Affiliation: Center for Occupational and Environmental Health, University of California, Irvine. 100 Theory, Suite 100, Irvine, CA 92617. b.choi@uci.edu

Refers to the following texts of the Journal: 2018;44(6):601-612 2003;29(3):206-215

Key terms: association; blood pressure; Brazil; demand-control; demand-control model; ELSA-Brasil; heterogeneity; hypertension; job control; job decision authority; job demand; job strain; Karasek; psychological stress; quantile regression analysis; systolic blood pressure

This article in PubMed: www.ncbi.nlm.nih.gov/pubmed/30358882 


\section{Positive association between job decision authority and systolic blood pressure: a statistical artifact?}

We read with great interest the paper by Juvanhol et al (1) on the association between demand-control model (DCM) components and blood pressure (BP) using the baseline data of the Brazilian Longitudinal Study of Adult Health (ELSA-Brasil). The authors reported a marginal, but positive cross-sectional association between job decision authority and systolic blood pressure (SBP) (0.59 mmHg, 95\% CI 0.00-1.18) among non-users of anti-hypertensives from five universities and one research institute (2). And they claimed that (in the contemporary world of work), "the health benefits of increasing decision authority may not be as evident as in the historical context where the DCM was developed, which was characteristically one of industrialization and repetitive tasks."

We agree with the authors that, in principle, the associations between psychosocial working conditions and health outcomes should be examined and interpreted with a socioecological perspective with consideration of societal and organizational structures and contexts (3). However, we could not find any convincing structureand context-based explanation of the authors for the positive association between decision authority and SBP, for example, one grounded in their in-depth understanding of detailed working conditions and contexts of the Brazilian workers at higher education institutes during 2008-2010. Instead, we have found serious weaknesses in their analyses and interpretations, which undermine their finding and claim.

First, the authors should have tested effect modification by race/color or socioeconomic status (SES) in their analysis. As expected, high decision authority was initially negatively associated with SBP among both users and non-users of anti-hypertensives (model 1, table 3) and also after controlling for gender, age, and recruitment site (model 2). However, only when race/color, schooling and mother's schooling were additionally included in their analysis (model 3), the direction of the association between decision authority and SBP changed from negative to positive among non-users of anti-hypertensives, while it substantially attenuated but remained negative among users of anti-hypertensives. Although the authors discussed these changes as a confounding effect of SES, it does not explain why the direction of the association was different between non-users and users of anti-hypertensives in model 3. In addition, there is a possibility of effect modification by race/color, schooling, or occupational class of their study participants (faculty and professional staff, technical and clerical workers, and unskilled workers) (2). The association between decision authority and SBP may differ by race/color or SES (education, income, or occupational class) $(4,5)$. Furthermore, the job strain hypothesis of the DCM was not also tested in the study.

Second, the authors should have tested the association between decision authority and SBP separately in normotensives and unmedicated hypertensives as well as medicated hypertensives. In their previous study (6), the authors demonstrated that BP distributions in the aforementioned three subgroups were very distinct to one another. Ignoring the distinct BP distributions between the two subgroups (normotensives and unmedicated hypertensives) in non-users of antihypertensives may have resulted in a bimodal BP distribution by a mix of two mononmodal distributions. Interestingly, in their quantile analysis, there was no significant association between decision authority and SBP in both ends of the SBP distribution among non-users of hypertensives that would more exclusively represent the SBP values of normotensives (the lower end) and unmedicated hypertensives (the upper end), respectively.

Third, the authors should have examined the whole distribution of exposure (decision authority) in their analysis. They used a median-based low and high decision authority variable for analyses. However, using the dichotomous variable can result in a substantial information loss and sometimes, attenuate or distort the real association with health outcomes $(7,8)$, particularly when the study population is not a random sample of general working populations. All participants in the ELSA-Brasil study worked for higher education institutes. And about $37 \%$ of them had postgraduate degrees. As a result, their study participants were characterized by relatively high job control and demands (6). In this situation, using a tertile- or quartile-based decision authority variable would be more appropriate for investigating the association between decision authority and $\mathrm{BP}$, including a possible non-linear relationship. In fact, decision authority was non-linearly associated with a clinical cardiovascular health score of blood pressure, fasting plasma glucose, and total cholesterol in a recent study with the same ELSA-Brasil study data (8).

Fourth, the marginal positive association between decision authority and SBP is also inconsistent with the 
finding of a previous study (8) with the same ELSABrasil study data in which high decision authority was positively associated with higher lifestyle cardiovascular health scores of diet, physical activity, smoking, and body mass index (higher scores mean better cardiovascular health). On the other hand, we would like to raise a question about the clinical implications of the marginal difference in the SBP, $0.59 \mathrm{mmHg}$ between the low and high decision authority groups reported in the paper.

Lastly, during the recent decades, the main principles of the 1918 Argentine Córdoba University Reform (university autonomy, co-government of all parties in universities, and no tuition from students) may have substantially eroded in Latin American countries (9) due to higher education policies with emphases on government control, privatization, efficiency, competitiveness, and partnerships with business. In this case, it would be more likely that many workers at higher education institutes (eg, non-tenure track, part-time faculty and researchers, clerks, janitors, and food-service workers) in Brazil, have suffered from low or decreasing rather than "excessive" decision authority on their tasks $(10,11)$.

Given all the above, we think that the authors' claim in the paper - "excessive" decision authority of workers as a source of stress in workers at higher education institutes in Brazil - is unsubstantiated and also misleading for societal and worksite efforts to improve workers' cardiovascular health. We suggest that the authors have collaborative and concrete discussions and qualitative investigations with their study participants about the contemporary working conditions and health issues of the workers at higher education institutes in Brazil. We believe that such approaches will further shed light on the underlying reasons for the marginal, but positive association between decision authority and SBP, which may be hardly captured by statistical analysis alone.

\section{References}

1. Juvanhol LL, Melo ECP, Chor D, Fonseca MJM, Rotenberg L, Bastos LS, Mill JG, Griep RH. Association between demand-control model components and blood pressure in the ELSA-Brasil study: exploring heterogeneity using quantile regression analyses. Scand J Work Environ Health. 2018;44(6):601-612. https://doi.org/10.5271/sjweh.3755

2. Aquino EM, Barreto SM, Bensenor IM, Carvalho MS, Chor D, Duncan BB, Lotufo PA, Mill JG, Molina Mdel C, Mota EL, Passos VM, Schmidt MI, Szklo M. Brazilian Longitudinal Study of Adult Health (ELSA-Brasil): objectives and design. Am J Epidemiol. 2012;175(4):31524. https://doi.org/10.1093/aje/kwr294.

3. Rugulies R. Invited commentary: Structure and context matters--the need to emphasize "social" in "psychosocial epidemiology". Am J Epidemiol. 2012;175(7):620-4. https://doi.org/10.1093/aje/kws033.

4. Choi B, Clays E, de Bacquer D, Karasek R. Socioeconomic status, job strain, and common mental disorders: an ecological (occupational) analysis. SJWEH Supplements 2008;(no 6):22-32 .

5. Landsbergis PA, Schnall PL, Pickering TG, Warren K, Schwartz JE. Lower socioeconomic status among men in relation to the association between job strain and blood pressure. Scand J Work Environ Health. 2003;29(3):206-15. https://doi.org/10.5271/sjweh.723.

6. Juvanhol LL, Melo ECP, Carvalho MS, Chor D, Mill JG, Griep RH. Job Strain and Casual Blood Pressure Distribution: Looking beyond the Adjusted Mean and Taking Gender, Age, and Use of Antihypertensives into Account. Results from ELSA-Brasil. Int J Environ Res Public Health. 2017;14(4). https://doi.org/10.3390/ ijerph14040451.

7. Karasek R, Choi B, Ostergren PO, Ferrario M, De Smet P. Testing two methods to create comparable scale scores between the Job Content Questionnaire (JCQ) and JCQlike questionnaires in the European JACE Study. Int J Behav Med. 2007;14(4):189-201. https://doi.org/10.1007/ BF03002993.

8. Rocco PTP, Bensenor IM, Griep RH, Moreno AB, Alencar AP, Lotufo PA, Santos IS. Job Strain and Cardiovascular Health Score (from the Brazilian Longitudinal Study of Adult Health [ELSA-Brasil] Baseline). Am J Cardiol. 2017;120(2):207-12. https://doi.org/10.1016/j. amjcard.2017.04.008.

9. Torres CA, Schugrurensky D. The political economy of higher education in the era of neoliberal globalization: Latin America in comparative perspective. High Educ. 2002; 43:429-55. https://doi.org/10.1023/A:1015292413037.

10. Mills N. The corporatization of higher education. Dissent (Fall 2012). Available from: http://www.dissentmagazine.org/ article/the-corporatization-of-higher-education.

11. Quinlan M1, Mayhew C, Bohle P. The global expansion of precarious employment, work disorganization, and consequences for occupational health: a review of recent research. Int J Health Serv. 2001;31(2):335-414. https://doi. org/10.2190/607H-TTV0-QCN6-YLT4.

BongKyoo Choi' ScD MPH, 1, 2, 3 Arturo Juárez-Garcia, PhD ${ }^{4}$

1 Center for Occupational and Environmental Health, University of California (UC) Irvine, USA.

2 Enviromental Health Sciences Graduate Program, UC Irvine, USA

3 Program in Public Health, UC Irvine, USA.

4 Center for Transdisciplinary Research in Psychology, School of Psychology, Universidad Autónoma del Estado de, Morelos, Mexico.

Correspondence to: BongKyoo Choi, ScD, MPH. Center for Occupational and Environmental Health, University of California, Irvine. 100 Theory, Suite 100, Irvine, CA 92617. [E-mail: b.choi@uci.edu]. 